- Revista de Iniciação à Docência, v. 2, n. 2, 2017 -

Publicação: março, 2018 - ISSN 2525-4332

\title{
LEITURA E LITERATURA NA ESCOLA NO UNIVERSO DA POESIA: RELATO DE UMA EXPERIÊNCIA COM ALUNOS DO ENSINO FUNDAMENTAL - SÉRIES INICIAIS
}

Alice de Oliveira da Purificação'

Elane Pereira Silva ${ }^{1}$

Marcela da Conceição Costa ${ }^{1}$

Tairana de Jesus Silva ${ }^{1}$

Antônia Claudia Cordeiro de Andrade ${ }^{2}$

RESUMO: Este relato de experiência descreve as etapas de elaboração e aplicação do projeto de intervenção "Leitura e literatura na escola no universo da Poesia", realizado em uma unidade escolar no contexto das séries iniciais do ensino fundamental. O projeto objetivou estimular o interesse pela leitura, contribuindo para a formação de alunos leitores, capacitados a interagir com o contexto em que estão inseridos. E de modo mais específico, observar a metodologia de ensino utilizada nas aulas de leitura; identificar possíveis lacunas existentes no processo de formação de alunos leitores; apresentar o gênero literário poesia de forma lúdica e criativa; promover a interação dos educandos com um texto literário do gênero poesia e contribuir com a formação crítica dos alunos por meio de práticas de leitura. Para tanto, realizamos observação in lócus; aplicação de formulários para dois alunos e de questionário à docente responsável pela turma. Posteriormente foi realizada a aplicação do projeto durante três dias. A aplicação do referido projeto permitiu a interação dos alunos com textos literários, incentivou a leitura por prazer, apontando para a importância de o professor ser leitor para formar leitores. Além disso, a nosso ver, o projeto possibilitou a vivência das estagiárias graduandas com o contexto escolar, relacionando teoria e prática.

Palavras-Chave: Leitura; Literatura; Formação de Leitores; Poesia.

\section{Introdução}

Este relato de experiência descreve as etapas de elaboração e aplicação de um projeto de intervenção denominado "Leitura e literatura na escola no universo da Poesia", realizado em uma unidade escolar no contexto das séries iniciais do ensino fundamental, localizada em uma comunidade quilombola da zona rural de Muritiba-BA, como requisito para avaliação parcial da disciplina Pesquisa e Prática Pedagógica III, ministrada pela professora mestre Antônia Claudia Cordeiro de Andrade, do curso de Licenciatura em Pedagogia da Faculdade Maria Milza, em Mangabeira-BA.

O projeto inicial teve como objetivo geral estimular o interesse pela leitura, contribuindo para a formação de alunos leitores, capacitados a interagir com o contexto

\footnotetext{
1 Graduandas do Curso de Licenciatura em Pedagogia, Faculdade Maria Milza, Mangabeira-BA. E-mail: marcellacosta01@hotmail.com

2 Docente do curso de Licenciatura em Pedagogia, Faculdade Maria Milza, Mangabeira-BA. E-mail: accacordeiro@hotmail.com
} 
em que estão inseridos. De forma mais específica pretendíamos também observar a metodologia de ensino utilizada nas aulas de leitura; identificar possíveis lacunas existentes no processo de formação de alunos leitores; apresentar o gênero literário "poesia" de forma lúdica e criativa; promover a interação dos educandos com um texto literário do gênero poesia e contribuir com a formação crítica dos alunos através da leitura.

Para alcançar tais objetivos, o projeto de intervenção trilhou a seguinte trajetória metodológica: i) observação in lócus; ii) aplicação de formulários para dois alunos e de um questionário à docente responsável pela turma; iii) aplicação do projeto durante três dias.

A execução do referido projeto se justificou por contribuir com o acesso dos educandos aos textos literários, possibilitando a compreensão de diversos gêneros textuais, favorecendo assim a construção da leitura de mundo dos mesmos. Fez-se relevante também, à medida que estimulou o interesse pelos textos literários, a fim de despertar a motivação dos alunos pela leitura, contribuindo para a formação de sujeitos leitores, além de fornecer subsídios teóricos e sugestões de atividades de leitura de poesias para professores em exercício e em formação; e permitir a vivência das estagiárias graduandas com sala de aula.

\section{Referencial teórico}

Faz parte das atribuições da escola ensinar a ler, escrever, como também, estimular o gosto pela leitura. Porém, observa-se que as instituições educativas têm falhado em alcançar tal propósito, notando-se um número cada vez maior de educandos não leitores. Eles têm dificuldade em enxergar o ato de ler como algo prazeroso, isso porque além de muitas vezes não serem estimulados no ambiente familiar, na escola as ocasiões e atividades de leitura acontecem apenas por obrigação.

Consideramos a leitura um fator de fundamental relevância na formação de um ser pensante e crítico, sendo por isso essencial o papel da escola na formação de leitores. De acordo com Frantz (2005):

Ler é atribuir sentidos. Nesse processo não se pode desvincular a capacidade do leitor de decifrar sinais da sua capacidade de atribuir-lhes sentidos. Somente a partir da realização desses dois momentos é que se poderá falar em leitura. Vista assim, a leitura se torna uma necessidade vital para o ser humano, indispensável à sua vida, pois lhe revela o seu próprio eu, ao mesmo tempo em que o instrumentaliza para melhor conhecer o mundo em que vive (p. 18).

O ensino de leitura nas séries iniciais proporciona aos alunos novas descobertas, além de contribuir com o seu desenvolvimento intelectual, cognitivo e social, porém, muitos educandos demonstram dificuldades na realização deste processo e sentem-se desmotivados quanto às atividades e práticas de leitura. 
A falta de motivação por parte dos alunos é considerada por Kleimam (2004) um fator intrinsecamente ligado às práticas docentes ligadas a tal questão. A autora afirma que para muitos alunos as atividades de leitura na escola estão distantes do ato prazeroso de ler como no aconchego do lar, que proporciona experiências marcantes e estimulantes.

Isso se deve ao fato de que o texto é geralmente usado em sala de aula como pretexto para atividades gramaticais ou simplesmente com fins de verificação da aprendizagem de leitura em voz alta, ficando em segundo plano o verdadeiro teor literário que o mesmo possui. Devido a isso os alunos acabam desenvolvendo a leitura somente por obrigação e não por prazer.

A leitura de textos literários proporciona ao aluno uma experiência prazerosa, trazendo-lhe possibilidades diferentes de perceber o mundo em que está inserido, além de conhecer os diversos gêneros textuais, como Frantz (2005, p. 24-25) assegura:

Acreditamos que é muito importante para o aluno a convivência com os mais variados tipos de texto, pois cada um revelará ao leitor uma faceta diferente da relação texto-mundo. Entretanto, para o aluno das séries iniciais é a leitura do texto literário a que deve predominar sobre as demais, por ser esse o texto que maiores afinidades têm com o leitor infantil, por ser um texto que envolve o leitor por inteiro [...].

Portanto, é essencial a ênfase em tais textos, dialogando com os saberes do mundo infantil e expandindo-os através da leitura, uma vez que os textos literários contribuem para transmitir o prazer cultural próprio das atividades artísticas.

Entre os gêneros literários, destaca-se a poesia, que é um gênero de grande importância principalmente para as séries iniciais, pelo seu caráter lúdico e por possuir uma linguagem com a qual as crianças têm contato desde a mais tenra idade e, por isso, a compreendem com facilidade. Apesar disso, este é um gênero pouco utilizado em salas de aula, pois é visto como "prima pobre da literatura"3, sendo que os docentes tendem a dar maior ênfase à prosa.

Os poemas facilitam a exploração do imaginário infantil através da sonoridade e dos jogos de palavras que encantam o universo da criança. De acordo com Frantz (2005):

A poesia atual privilegia o aspecto lúdico, a sonoridade, o jogo de imagens e de palavras. Fala de coisas do mundo infantil sem preconceito, sem querer fazer a cabeça da criança, sem apelar para uma linguagem piegas, sem nenhuma outra intenção que não seja brincar com as palavras e mostrar o mundo por meio de uma linguagem lúdica e poética (p. 86).

Essas características da linguagem poética tornam o trabalho com esse gênero em sala de aula um exercício de criatividade e prazer pela leitura.

\footnotetext{
${ }^{3}$ Termo utilizado por Frantz (2005) no livro "O ensino da literatura nas séries iniciais".
} 


\section{Metodologia}

O projeto de intervenção foi realizado em uma unidade escolar da rede municipal de ensino, situada em uma comunidade quilombola, localizada na zona rural da cidade de Muritiba-BA. Este trabalho teve como público alvo uma turma do segundo ano do ensino fundamental séries iniciais, composta por 15 alunos.

O projeto foi desenvolvido em duas etapas, sendo realizada primeiramente um conjunto de observações das aulas dedicadas à leitura na classe selecionada. A ideia dessas observações foi conhecer a metodologia de ensino da educadora e a condição dos alunos quanto à sua formação como sujeitos leitores.

Também foram aplicados formulários para dois alunos escolhidos aleatoriamente, com a finalidade de observar as atividades sob a ótica destes educandos e entregue um questionário à docente responsável pela turma, contendo perguntas concernentes às suas práticas de leitura e sobre a aplicação das mesmas em sala de aula.

A segunda etapa consistiu em uma intervenção distribuída em dois dias, que intencionou encantar os alunos pelo gênero textual "poesia", promovendo o contato com diversas poesias, contribuído assim para formação de alunos leitores.

\section{Resultados e discussão}

Durante a observação foi constado que a professora estimula o hábito de leitura em sala de aula, disponibilizando livros literários para os alunos escolherem para ler e/ou para ela fazer a leitura para eles. Também foi observado que a docente reserva um tempo no início ou no final de cada aula para leitura com as crianças, e que a mesma utiliza diversos gêneros literários como as poesias e os contos de fadas.

Notou-se que as aulas de leitura desta classe estão em conformidade com as propostas formuladas por Kleimam (2004), pois a educadora não usa os textos literários como pretexto para o ensino de regras gramaticais, e sim para proporcionar momentos de leitura agradáveis e estimulantes na sala de aula.

No que tange a estrutura física favorável à leitura, foi verificado que a escola não possui biblioteca, mas que a sala de aula conta com livros literários e que os alunos têm livre acesso a eles.

Em relação aos formulários, os alunos relataram que gostam de ler e que a professora conta histórias em sala de aula. Eles afirmaram ainda que entre as histórias que a professora já contou, a que eles mais gostaram foi a "Estrelinha Atrapalhada". A primeira criança contou que ela gosta muito de ler nas aulas de leitura, enquanto a segunda criança disse o que ela mais gosta de fazer é reescrever histórias, revelando que eles são motivados para a leitura de textos literários. 
O aluno de número 1 informou que o que menos gosta nas aulas de leitura é reescrever histórias e o aluno de número 2 afirmou gostar menos de matemática, fugindo do foco da questão. Eles também relataram que possuem livros em casa. Quando questionados se as pessoas que moram com eles costumam ler para os mesmos, o primeiro relatou que a mãe realiza essa tarefa; e o segundo respondeu que não tem quem faça isso para ele.

É possível observar no questionário aplicado à professora, que ela indicou ser formada em Pedagogia e especializada em Psicopedagogia; a mesma afirmou incentivar o ato de ler em sala de aula, encorajando os alunos a escolher um livro para a leitura semanal e outro para a roda de leitura.

Ela também disse que existem aulas destinadas à leitura em sala de aula, e que trabalha vários gêneros literários no contexto das aulas como poesias, contos de fadas e histórias em quadrinhos. Informou ainda que nas aulas utiliza com frequência as práticas de leitura com o emprego de livros didáticos, paradidáticos, livros de poesias e livros de contos de fadas.

A docente relata ainda não encontrar dificuldades para trabalhar leitura de textos literários em sala de aula, pois tem a sua disposição uma variedade de livros oferecidos pelo Projeto Pacto Nacional pela Alfabetização na Idade Certa. Ela continua contando que tem o hábito de ler e diz ter lido nos últimos anos livros infantis e outros.

Durante o primeiro dia de intervenção desenvolveram-se atividades que objetivaram familiarizar os educandos com o gênero estudado, isto é, as poesias. Nesta ocasião houve oportunidade para que os estudantes conhecessem diversas poesias e autores. A aula foi iniciada com um levantamento dos conhecimentos prévios dos alunos, por meio de problematizações referentes ao gênero literário "poesia". Em seguida, foi informado aos alunos que eles iriam conhecer mais sobre este gênero no decorrer da aula. A seguir, foi feita a declamação dramatizada da poesia "Viagem" de Fernando Paixão (2005), atividade que envolveu todos os educandos.

Posteriormente, realizou-se uma roda de conversa na qual foram apresentadas poesias musicadas, imagens de autores de poesias, poesias e livros de poesias com o auxílio do suporte da "Lata do TudoNada" que é sugerido pela música "Metáfora" de Gilberto Gil. Essa lata circulou pela roda de alunos ao som da música "Latinha que passa-passa, latinha que já passou, quem ficar com a latinha uma poesia tirou!", inventada pelas estagiárias. Nesta atividade cada criança teve o direito de retirar uma poesia de dentro da referida lata, que foi lida pelas aplicadoras da atividade.

Ao final da roda, foi proposto aos alunos um jogo de quebra-cabeça, formado por textos poéticos e não poéticos, sendo que só se encaixaram as poesias. Intencionou-se com este jogo que as crianças identificassem as poesias. Durante o desenvolvimento das atividades foram registradas a participação e o entusiasmo dos alunos. 
No segundo dia de intervenção pretendeu-se despertar nos alunos o interesse pela leitura de poesias, por meio da ludicidade e do dinamismo. Nesse dia, verificaram-se os conhecimentos anteriores das crianças sobre a poesia "o gato" de Vinícius de Moraes (2016) através de questionamentos referentes à mesma. E os alunos foram convidados, por meio da declamação da poesia "Convite" de José Paulo Paes (2016), a se encantarem com o mundo da poesia.

Depois foi feita a dramatização com fantoches da poesia "O gato" de Vinícius de Moraes, e posteriormente cantou-se com os educandos esta poesia. A seguir foi aplicada uma atividade escrita referente à poesia. Em continuação, realizou-se uma dinâmica em que as crianças puderam brincar com as rimas. Esta atividade se desenvolveu da seguinte forma: a turma foi dividida em dois grupos; em cada rodada um integrante de cada equipe correu até certo ponto, pegou um balão, voltou para o seu grupo, estourou o balão e ganhou o direito de completar a frase que foi retirada de dentro do balão, com uma palavra que rimasse com uma parte do corpo. Exemplo: Eu vi, eu vi um coelho ele queria subir no meu ... (joelho). Em seguida, foi entregue aos alunos um livrinho de poesias para leitura e atividade de colorir, como estímulo para eles continuarem a ler e também um saquinho de doces.

Com o desenvolvimento do referido Projeto, as crianças da classe selecionada se encantaram com a dramatização da poesia "Viagem" de Fernando Paixão (2005), e conheceram diversas poesias e autores de maneira lúdica e criativa. Também puderam identificar as características do gênero literário poesia por meio do quebra-cabeça composto de poesias e textos não literários.

No segundo dia de intervenção os alunos foram envolvidos pela declamação da poesia "Convite" de José Paulo Paes, e se encantaram com a dramatização da poesia "O gato" de Vinicius de Moraes. Nessas atividades constatamos que os alunos conseguiram demostrar nas atividades impressas que foram capazes de relacionar o som de uma palavra com o de outra, e na dinâmica mostraram que também conseguiram formar rimas.

\section{Considerações finais}

A experiência descrita aponta sugestões para o trabalho com textos literários no universo da poesia, para estimular os educandos a ler por prazer, sem a obrigação de realizar uma atividade de natureza mais formal. Percebeu-se a importância dos professores gostarem de ler e fazer disso um hábito para poder também formar leitores. Notamos ainda a relevância do educador promover momentos de leitura em classe, disponibilizar para os alunos livros de literatura e outros portadores de texto.

Para finalizar, podemos assinalar que a execução do projeto de intervenção oportunizou o confronto entre as teorias estudadas e a realidade vivenciada pela classe observada, além de contribuir para a formação das estagiárias possibilitando a vivência do contexto da sala de aula, colocando em prática os conhecimentos adquiridos na academia. 


\section{Referências}

FRANTZ, M. H. Z. O ensino da literatura nas séries iniciais. Unijuí/RS: Ijuí, 2005.

KLEIMAM, Â. Oficina de leitura: teoria e pratica. 10 ${ }^{\mathrm{a}}$ ed. Campinas, SP: Pontes, 2004.

MORAES, V. O gato. Disponível em: http:www.viniciusdemoraes.com.br. Acesso em: 04 de outubro de 2016.

PAES, J. P. Poemas para Brincar. São Paulo: Ática, 2016.

PAIXÃO, F. Viagem. In: LISBOA, H. et al. Varal de Poesias. São Paulo, Ática, 2005. 